Towards an Understanding of Cloud Computing's Impact on Organizational IT Strategy

By: Ruoning Qian and Prashant Palvia.

Qian, R., and Palvia, P. (2014). "Towards an Understanding of Cloud Computing's Impact on Organizational IT Strategy". Journal of IT Case and Applications Research. 15 (4), 3454.

***@ Taylor \& Francis. Reprinted with permission. No further reproduction is authorized without written permission from Taylor \& Francis. This version of the document is not the version of record. Figures and/or pictures may be missing from this format of the document. $* * *$

This is an Accepted Manuscript of an article published by Taylor \& Francis in Journal of IT Case and Applications Research on 07/07/2014, available online: http://www.tandfonline.com/10.1080/15228053.2013.10845727

\begin{abstract}
:
Cloud computing has become a dominant IT trend during the past two years for its potential to remarkably change the technology and the business landscape. Although a lot have been discussed regarding its benefits and risks, and cloud strategy itself has been widely studied in the business world, its strategic impacts have not yet been fully addressed. In order to understand how cloud computing is going to bring changes to the overall IT strategy of the organization, we conducted interviews with CIOs/IT directors from 4 US companies which have adopted cloud computing services to understand such impacts. Grounded theory approach was used in this study and a model was generated based on qualitative analysis. Our findings reveals that, cloud computing has profound impacts on various aspects of organization's overall IT strategy: including IT architecture, IT management, data strategy, and IT/ business alignment. Given the trend that more and more organizations are going to embrace cloud computing, the model and findings of this research would have great both research implications for future investigators as well as practical implications for organizations.
\end{abstract}

Keywords: Cloud Computing | IT Strategy | Strategic Adoption | Case Study | Grounded Theory

Article:

\title{
INTRODUCTION
}

Cloud computing has become a dominant IT trend during the past few years. According to a recent IDC report in 2012, investments in cloud services adoption have exceeded $\$ 36$ billion, representing a $28 \%$ increase from the previous year and a four-time growth rate than the industry overall (Gens, 2012). The trend is enabled by the rapid development of high speed internet connectivity and the decreasing cost of storage (Hyek, 2011), and is expected to continue in the upcoming years. Having emerged as a disruptive technology, cloud computing (or simply "the cloud" as it is commonly abbreviated) offers an alternative to the traditional way of providing 
and delivering information services, and such an alternative is expected to have considerable impact on the entire organizational IT strategy. According to a recent survey conducted by Enterprise Strategy Group (ESG), 72\% of the CIOs believed that the cloud is going to have significant impacts on their companies' IT strategy in the coming five years (Lundell, McKnight and Gahm, 2011).

Understanding such impact is quite important in ensuring the strategic adoption of the new technology, which has the potential to transform the organization. Although cloud computing has been discussed a lot in both business and academic world regarding its potential benefits and risks (Avanade, 2009; Catteddu, 2010; MotahariNezhad, Stephenson and Singhal, 2009) and many have examined its value from the strategic adoption point of view (Hosseini, Greenwood and Sommerville, 2010; Misra and Mondal, 2010), few has focused on its impacts from an organization's IT strategy perspective. As such a general framework to illustrate the strategic impacts of the cloud is both needed and will be very useful. Motivated by this need, this study strives to identify the strategic level impacts of the cloud by using the grounded theory approach to generate a framework for understanding the phenomenon. Based on the qualitative analysis, we are able to address the following research questions: 1) Does the adoption of cloud based technology/service affect an organization's overall IT strategy? 2) Which aspects of the IT strategy are affected and how?, and 3) What are some important implications for organizations?

The following section briefly reviews the literature on cloud computing and its impact and organizational IT strategy and its various subcomponents; followed by the methodology section which describes the steps in data collection and analysis; the analysis and findings are then presented in a narrative manner, based on which an impact model is generated and presented; in the end the contributions and limitations of this study are discussed as well as the conclusion.

\section{LITERATURE REVIEW}

\section{Cloud Computing, Benefits and Risks}

The term 'Cloud Computing' has been around for years. Previous studies have defined cloud computing from various perspectives. Buyya, Yeo, Venugopal, Broberg and Brandic (2008) define cloud computing as "parallel and distributed, inter-connected and virtualized computers system which are dynamically provisioned and presented as one or more unified computing resources". Mell and Grance (2009) from National Institute of Standards and Technology (NIST), defined cloud computing as "a model for enabling convenient, on-demand network access to a shared pool of configurable computing resources (e.g., networks, servers, storage, applications, and services) that can be rapidly provisioned and released with minimal management effort or service provider interaction". Based on the above definition, the five essential characteristics of cloud computing are summarized as: on-demand self-service, broad network access, resource pooling, rapid elasticity, and measured service.

Due to the above characteristics, cloud computing is perceived to have a great potential to generate various benefits for organizations, including cost related benefits such as elimination of up-frontal cost and operational/maintenance costs, and increased savings on overhead procurement (Motahari-Nezhad et.al, 2009); business performance related benefits such as 
increases agility in the deployment of firm initiatives, increased speed, elasticity, flexibility, and scalability of service delivery, and increased focus on core business (Avanade, 2009; Ahuja \& Rolli, 2011), etc. However, as cloud computing has not yet passed its stage of infancy and reached maturity, there are still several issues such as security (Catteddu, 2010), legal issues, and privacy issues (Joint, Baker and Eccles, 2009), vendor trust issues (Ward and Sipior, 2010) etc., thereby making evaluation of cloud's impact rather complex.

A stream of literature on cloud computing adoption has put considerations of benefits/risks within the organizational strategic adoption and decision making context. Misra and Mondal (2010) analyzed some of the economic aspects of adopting cloud architecture, taking into consideration various intangible impacts of cloud computing apart from the cost. Their research provided a useful management tool for fully assessing the cost benefits of the cloud.

Hosseini et.al. (2010) illustrated the potential impacts of migrating IT system to the cloud both financially and technically. They found that migration is able to reduce the infrastructure cost, and to reduce support calls to the IT department. However, other impacts such as customer satisfaction, overall service quality due to transfer of control to third parties, employee job satisfaction due to changes in nature of work, long term cost volatility in terms of cloud-usage and data transfer costs and etc. need to be taken into account and have not been carefully examined.

lyer and Henderson (2010) went beyond the financial and technical evaluation, and suggested several necessary IT governance considerations after the adoption of cloud computing such as the decision on who will have the access to the services; understanding of the implications on IT roles and governance including the possibility of creating of new job opportunities and the need to incorporate third parties, and being aware of the effects on network based competition.

There have been a number of research efforts regarding the strategic considerations of cloud adoption and the one commonality of these studies is that they not only focused on the static evaluation of the impacts in terms of benefits and risks, but they also suggested that it is important to understand the dynamics between the cloud and the organization's existing structure, resource and strategy.

The above research literature provides sufficient evidence that the adoption of cloud computing is going to have substantial strategic impact on the organization; however clearly no integrated framework has been provided to fully understand such impact. Thus our work is an endeavor to contribute to the literature by filling this gap.

\section{IT Strategy and Sub-Components}

In order to understand the cloud's impact on IT strategy, it is important to understand the nature and scope of the term "IT strategy", which has been often readily used but seldom explicitly defined. One of the earliest attempt to understand IT strategy came from King (1978), who tried to position I/T strategy in the corporate strategic hierarchy (corporate, business, and function) as the functional level strategy, with a charter of "efficiently allocating its resources to best support the business strategy". In Gottschalk (1999)'s work, IT strategy is defined as it relates to the 
organizational strategy as "a plan comprised of projects for application of information technology to assist an organization in realizing its goals". Recently, Chen, Mocker, Preston, and Teubner (2010) argued that, ISIIT strategy should have an identity of itself rather than defined through either business strategy or organizational strategy. They reviewed the past research on IS/IT strategy and defined IS/IT strategy as "an organizational perspective on the investment in, deployment, use, and management of information systems."

Some of the literature has tried to identify several important components of IT strategy. Baets (1992) started from the overall corporate strategy, and used the information pyramid to detail the IS strategy as: desired IT architecture, technology used and available, data structure and database design, and so on. Henderson and Venkatraman (1993) articulated the IT strategy in terms of both external and internal domains; the external domain addresses IT's supportive role in positioning the organization in its market place including: IT scope, system competence and IT governance; the internal domain concerns the internal structure and skills in supporting the organization's business processes which include: IT architecture, IS process, and IT skills. Glaser (2006) showed that IT strategy has an obvious focus on applications, IT infrastructure, data strategies, IT staff, and IT governance. Cuenca, Ortiz, and Boza (2011) synthesized previous works to identify several components of IT strategy as: IT Scope, capability and skills, governance, application portfolio, business/IT alignment maturity, and data strategy.

We regrouped some of the sub-components of IT strategy based on the above conceptualizations; our categorization of IT strategy is presented in Table 1.

\section{RESEARCH METHODOLOGY}

Since the strategic impact of cloud computing is a relative new area of research, there is no major theory or framework that can be readily be used. Therefore in this study, we use the grounded theory approach. Grounded Theory is a research method developed by Glaser and Strauss (1967), "aiming to generate theory through inductive examination of data in subject areas that may be difficult to access with traditional quantitative research methods" (Strauss and Corbin, 1994). This is different from the hypothetical-deductive method, where theories are generated from testing and refining of a previously constructed hypothesis.

In order to conduct the grounded research, we needed to identify organizations which were involved in using cloud services as well as senior managers who were willing to provide deep insights. We had an initial list of companies for which we had contact information. We sent out emails to these companies with the following screening questions:

1. Has your company adopted cloud services in the past two years?

2. Do you agree that the cloud service you adopted has a certain level of impact on your overall IT strategy?

Companies with an answer of "Yes" to both questions were selected as our candidates. Note that for the initial study, the size of the company or the industry were not important considerations for us. While it is possible that different types of cloud services (e.g., public, private etc.), 
organizational characteristics and the industry may have different impacts on the IT strategy, our goal was to develop an initial understanding and generating a general model which will serve as a starting point; specific nuances should be the subject of future research. Out of the ten companies we contacted, seven companies had adopted some kind of cloud services and four agreed that the cloud had an obvious impact on their IT strategy. We then selected key informants/experts from these four companies. We interviewed the Senior IT executives/Director of each organization in order to obtain a strategic perspective. Four experts were identified, one from each organization.

\begin{tabular}{|l|l|l|}
\hline \multicolumn{1}{|c|}{$\begin{array}{c}\text { IT Strategy } \\
\text { Sub- } \\
\text { Component }\end{array}$} & \multicolumn{1}{|c|}{ Literature } & \multicolumn{1}{c|}{ Definition } \\
\hline $\begin{array}{l}\text { IT Architecture } \\
\text { (infrastructure, } \\
\text { technology, } \\
\text { system, } \\
\text { application) }\end{array}$ & $\begin{array}{l}\text { Baets (1992) - IT architecture, technology; } \\
\text { Henderson and Venkatraman (1993) - } \\
\text { Glaser (2006) - IT infrastructure; } \\
\text { Cuenca et.al (2010) - Application portfolio }\end{array}$ & $\begin{array}{l}\text { IT architecture is the } \\
\text { organizing logic for } \\
\text { applications, data and } \\
\text { infrastructure technologies, as } \\
\text { captured in a set of policies } \\
\text { and technical choices, e.g., } \\
\text { storage, network, applications, } \\
\text { physical devices etc.(Ross, } \\
\text { 2003) }\end{array}$ \\
\hline $\begin{array}{l}\text { Data Strategy } \\
\text { IT Management } \\
\text { (process,skills, } \\
\text { service, staff) }\end{array}$ & $\begin{array}{l}\text { Baets (1992) - data structure and database } \\
\text { design; } \\
\text { Henderson and Venkatraman (1993) - data } \\
\text { strategy; } \\
\text { Glaser (2006) - data strategy; } \\
\text { Glaser (2006) - staff, governance; } \\
\text { Cuenca et.al (2011) - capabilities and } \\
\text { skills, governance }\end{array}$ & $\begin{array}{l}\text { Data strategy reflects all the } \\
\text { ways to capture, store, } \\
\text { manage and use data and } \\
\text { information. Include storage, } \\
\text { processing and retrieval etc. } \\
\text { Baets (1992) }\end{array}$ \\
\hline $\begin{array}{l}\text { IT/Business } \\
\text { alignment }\end{array}$ & $\begin{array}{l}\text { Cuenca et.al (2011) - Business/IT } \\
\text { alignment maturity }\end{array}$ & $\begin{array}{l}\text { Judicious organization of } \\
\text { technological means to } \\
\text { accomplish individual and } \\
\text { social goals. Includes IT } \\
\text { process, service, staff } \\
\text { management, and IT } \\
\text { governance (Magoulas \& } \\
\text { Pessi, 1998) }\end{array}$ \\
\hline $\begin{array}{l}\text { The extent to which the IS } \\
\text { strategy supports, and is } \\
\text { supported by, the business } \\
\text { strategy" (Luftman, Lewis and } \\
\text { Oldach, 1993) }\end{array}$ \\
\hline
\end{tabular}

Table 1: IT Strategy Sub-Components

We conducted in-depth interviews with the key informants using a semi-structured questionnaire (see appendix). In order to facilitate the subsequent analysis, we used the categorization of the various sub-components of IT strategy which was developed from the literature (see table 1). It was understood that a clear definition and mutual agreement on IT strategy and its sub- 
components during the interview is very important. In the grounded theory approach, the objective is to learn from the knowledge of the subjects and avoid the trappings of positivist research. Therefore, we let the interviewee talk about the impacts of the cloud naturally and freely from various perspectives. At the end, these perspectives in all cases could be classified by the categories represented in Table 1. Whenever there was doubt, the interviewer and the interviewee were able to jointly place specific items into the categories (these were also called sections). All four interviews were conducted separately during two weeks and each lasted for about 45-60 minutes. They were conducted over the phone or face to face. All the interviews were audio recorded. Follow-up interviews for clarification were conducted during the week following the initial interview.

After all the interviews were conducted, the audio records were transcribed into text for analysis purposes. There were three steps in carrying out the analysis: 1) Independent coding to extract themes under different sections. Although the answers from each expert were pre-categorized by sub-components of the IT strategy, under each sub-component there might be different themes based on various perspectives of the impacts. In order to get these different themes, we read through all the sections and coded the themes; 2) Cross checking the codes for each theme: for each theme under each section of each interviewee, we compared the coded themes and resolved some of the minor differences; then the coded themes were sent back to the interviewee to confirm that we have understood them correctly; any misunderstanding was resolved at this time; 3) Generating common themes under each sub-component: the final step is to extract the common themes across the interviewees. Themes that appear twice or more were included in our model. Any theme mentioned by only one person was removed as being a special case. After all the analysis was done, the common themes were organized under each sub-component of IT strategy. Figure 1 shows the method and the levels of analysis.

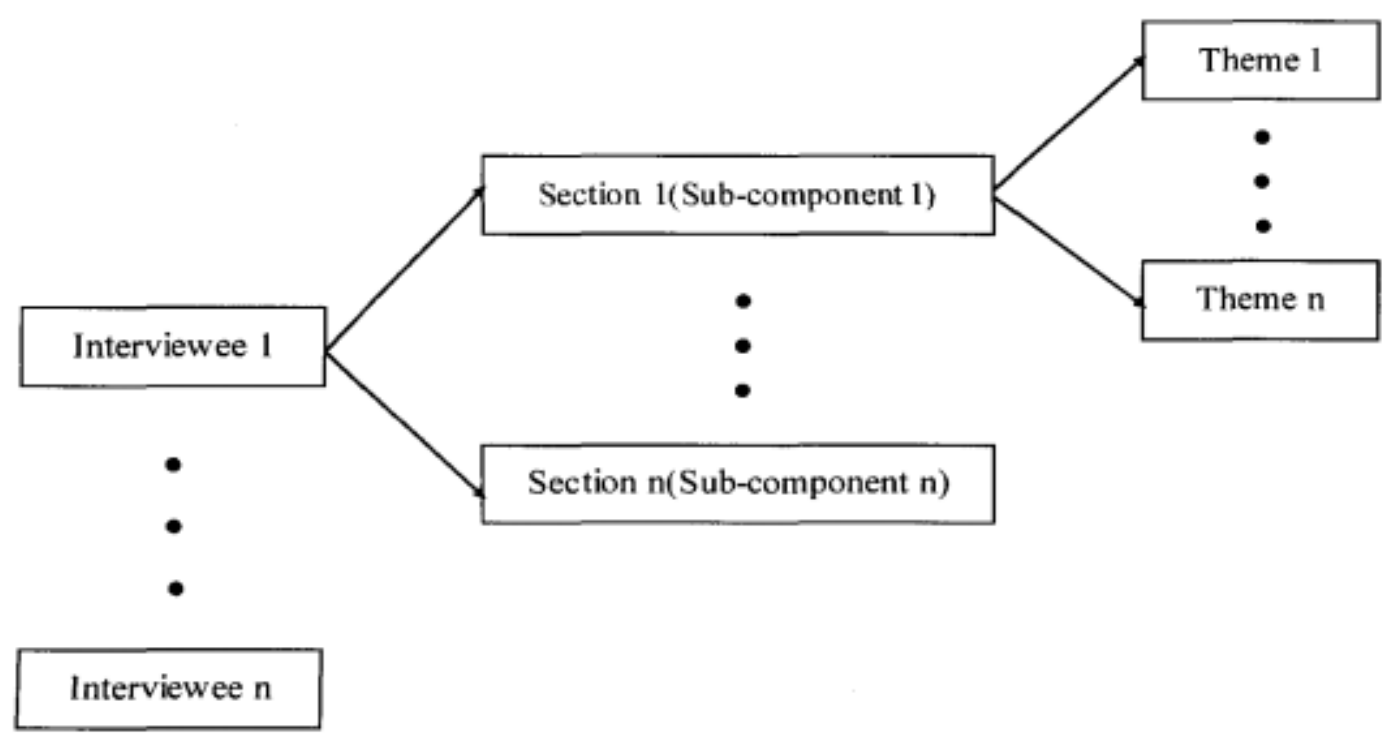

Figure 1: Method and Levels of Analysis

\section{ANALYSIS AND FINDINGS}


Following the above steps, we were able to identify the following themes grouped under the various sub-components of IT strategy. The findings are reported as a combination of secondary narratives and direct quotes from our interviewees.

\section{Impact on IT Architecture}

\section{Enabling Scalable IT Architecture:}

In order to provide reliable support, IT implementations should always be designed to handle both peaks and valleys of application usage. The inefficiencies during non-peak hours due to the overprovisioning in trying to accommodate the maximum demand were inevitable in the past. However, by utilizing the on demand service mode of the cloud, organizations do not need to maximize the provisioning capability in order to sustain such reliability. Traditionally, the whole process of including a new application into an existing IT architecture was complex, timeconsuming and costly. In addition, IT architecting always requires cautious thinking, and planning the changes required across the entire IT environment needed to be predicted and prehandled. This is how the existing IT architecture can sometimes impede the adoption of technology innovation. This put more emphasis and pressure on previously well-developed IT initiatives. The scalability brought by cloud requires a different approach and mindset for IT architecting. As one key informant said:

"Organizations have never experienced such high level of scalability before the age of cloud, but the mindset for adapting to this level of scalability is more important, you need to know how to transform from static to dynamic, from relying on a thoughtful, long run pre-planning to quick catch up with latest technology development".

Requiring a Long-term Cloud Integration Strategy: For organizations that have adopted cloud based services, the IT managers emphasize the important of ensuring a smooth integration of the cloud into existing business solution portfolio, application platforms and systems. Meanwhile, they also need to be aware of the integration between several cloud services which are often provided by different vendors.

Cloud Integration can be relative simple at first, but it can become more and more complex later on as the number of applications and service providers increase.

"The fact is, the more endpoints you have with different vendors, the more complex this coordination and integration becomes, so sometimes you need to think from the start in order to have a cohesive sourcing strategy for integration ".

In addition, the APIs themselves are not unchangeable; organizations should always be prepared for a constantly evolving set of APIs with expanded functionality. Other than having an integration strategy in place to deal with the possible errors, exceptions, and customization requirements, both "cloud-to-cloud" and "cloud-to-ground" integration should take future needs into considerations. A long-term integration strategy is quite necessary.

From Data Storage Centric to Web Centric: According to some of the IT directors: 
"Spreading out the service in the virtualized cloud is sometimes a strategy to mitigate the risk associated with traditional data center disasters ".

However, cloud has centralized the role of web connectivity; thus both the speed and reliability of the web matter. Nowadays, many of the office applications have been moved to the cloud, and to use any of these services you will need internet connection. A slow Internet connection can become a great impediment to productivity. Also, while in-house system can benefit from fast LAN connectivity, bandwidth resources are much scarcer and more expensive in the long run to support cloud services.

Although web connectivity is always important, some of the IT directors mentioned:

"In the age of cloud, it becomes huge. Imagine an internet connection breakdown, we can be put to a total paralysis with all the data on the cloud server. We can do nothing ourselves."

Organizations are experiencing shifted risks from data center disaster to web connectivity. Also, web security is becoming more and more important. Instead of having all the data within the intranet, some of the crucial data is being transferred through the public Internet which is more vulnerable to attacks. Although this problem does not exist if adopting a private cloud, for public cloud this is a huge issue.

Virtualization and Mobile Strategy: These sub-strategies are important as stated by one IT Director:

"One of the major implications of cloud is virtualization and the increasing connection of mobile devices."

Cloud is not only just virtualized computers and storage; it is a whole virtualized network which enables a much higher level of physical infrastructure independency. Meanwhile, an increasing numbers of mobile devices are being connected to the cloud.

"We always find that, cloud based services and use of mobile devices come hand in hand, both in combination provide huge implications for further strategic level transformation, such as mobile enterprise, which means being able to connect to the services from anywhere. " As previsioned by some directors, cloud is just a beginning of the transition to a modern IT environment, which requires years of planning and efforts ahead to go through the transformation from old school IT architecture philosophy into the modern new ones. This is more of a long-term strategic level change that starts with cloud."

The impacts of the cloud on organizational IT architecture are summarized in Table 2. 


\begin{tabular}{|l|l|}
\hline Traditional IT architecture & IT architecture for Cloud \\
\hline $\begin{array}{l}\text { Static, well pre-planned, depends on existing } \\
\text { initiatives }\end{array}$ & Scalable and dynamic \\
\hline Static and overall integration plan & $\begin{array}{l}\text { Cloud to Cloud, Cloud to Ground } \\
\text { integration; require dynamic and long- } \\
\text { term strategy }\end{array}$ \\
\hline Data Storage Centric & Web connectivity and security centric \\
\hline Physical infrastructure \& PC end connection & $\begin{array}{l}\text { Virtualized and increased mobile device } \\
\text { connection }\end{array}$ \\
\hline
\end{tabular}

Table 2: Cloud's Impact on IT architecture

\section{Impact on IT Management Shift to Service Oriented Management:}

One of the revolutionary aspects of the cloud is that IT is now being provided and delivered as a service, which indicates a shift in IT managerial focus. According to some of the directors, they are managing IT quite differently from before with different emphasis. Rather than managing the physical infrastructures and technology details, they are managing a solution with emphasis on its effectiveness in tackling different business tasks. They are managing a service, with emphasis on service delivering efficiency and cloud service customization. They are managing a relationship with different service providers with focus on vendor performance and contract management. As one of them said:

"Managing a new viable tool for us, with emphasis on how to better leverage it for business value generating."

New management tasks have also emerged with having to leave the details to the vendors. As our informants said:

"You have to remain in good communication with these people, you have to know every detail, although you are not the people to handle them in actual. The management cost turns into communication and coordination cost."

"Also, splitting the task and responsibility is another issue that should be taken care of at the start; do not wait until something happens and nobody has taken responsibility. Here is the moment when IT is standing at the front end to handle relationship with vendors. "

Leveraging IT Force More Strategically: Contrary to the hype that the cloud promises to reduce IT headcounts, our investigation indicated that adopting a cloud based service that is run and provided outside the company wall does not necessarily result in a decrease in IT headcounts. Although efforts required for actually running and maintaining the data center, such as systems and other physical infrastructure, may decrease at some level, companies still need to hire people to manage the cloud services, e.g., to configure and customize services for their own users. The difference lies in the skill set that are required from the IT specialist: 
"Now, we need to hire someone who have mastered the programming language to interface with the cloud."

However, for companies which are experiencing a rapid business growth, cloud has successfully prevented IT headcounts from growing with the increasing information needs and workloads.

"Maintaining our staff at a certain level when we are experiencing a rapid expansion is another way of reducing the heads related cost."

More important than reducing the IT heads related cost, however is "to be able to use the heads more strategically". One of the underlying promises of cloud adoption is to emancipate the IT force from routine tasks pertaining to technical details and to be able to focus on the parts where real business value and competitive advantages can be generated. For example, in the case of higher education:

"The real competitiveness lies in academic research; now, cloud is allowing our people to focus on creating an IT environment to better facilitate our research activities rather than maintaining the physical infrastructures."

\section{Requiring a Balanced Cloud Sourcing Strategy: One IT Director observed:}

"Cloud makes traditional IT outsourcing obsolete, and it is critical to have a well-defined Cloud sourcing strategy."

The underlying motivation of IT outsourcing is the cost benefit advantage and the perceived greater capability of the service providers. Most IT directors said, they believe that, with the specialization of expertise and economics of scale, the vendors can meet the user and customer requirements with lower cost and more reliable performance.

However, with the increasing numbers of cloud services, organizations are faced with an increasing amount of challenges posted by managing multiple vendors. As one director said:

"You will have to engage more in vendor selection and reliability assessment, contract execution and documentation, and vendor performance monitoring, etc.; sometimes you will have to balance between choosing service from a different vendor to prevent vendor lock-in, and choose services from the same vendor to avoid more API conflicts related issue."

The following table summarized the impacts of cloud on IT management: 


\begin{tabular}{|l|l|}
\hline Traditional IT management & IT management in the age of cloud \\
\hline Physical infrastructure management & Service oriented management focus \\
\hline $\begin{array}{l}\text { IT staff engaged in routine task and system } \\
\text { maintenance }\end{array}$ & $\begin{array}{l}\text { Engage in more value/competitive } \\
\text { advantage generating activities }\end{array}$ \\
\hline Internal management & $\begin{array}{l}\text { Balanced Cloud sourcing strategy with } \\
\text { focus on vendor relationship management }\end{array}$ \\
\hline
\end{tabular}

Table 3: Cloud's Impact on IT Management

Impact on Data Strategy

Requiring Incremental Data Migration strategy: Moving current data and services to the cloud is among the first few things that should be dealt with immediately from the very start of the cloud deployment.

"You need to ask three questions: first, what to migrate and what not to; second, how to? What tool to use? Time span for doing this migration; third, what is the worst situation and the result if any chance the data got lost?"

The mapping between the origin and the target is important. By doing this, organizations will understand how their data can be supported and reused in future. Also, organizations should be aware of the risks associated with data migration. As data/service migration sometimes needs to be carried out incrementally, it requires a carefully crafted plan to ensure database integrity during the whole process.

More considerations are required when organization make the decision to move more services to the cloud:

"After savoring the success of your first migration, you will be constantly asking the question:, what else could be moved to the cloud in the future."

Requiring New Data Control Strategy: For many organizations, a sense of losing control over the corporate data is quite common, especially in the case of public cloud. This loss of control is mainly two-folded: organizations don't know where the data is being kept and who have the access to the data. One of the major characteristics of cloud computing is that, it is based on virtually pooled resources, which is always location independent. Lack of location information can increase organizations' concerns over its integrity and privacy. Meanwhile, since the data is managed by vendors, the company would normally assume that at least the data administrator on the provider's side have access to the data, thus arousing concern over data privacy.

Although, according to several of the companies, there is not much they can do when data goes out, they still try to do whatever they can to exert certain control over data, only by adopting a different data control strategy. Instead of securing the data storage and transfer by themselves, they try to ensure data integrity by demanding better transparency of the service. Meanwhile, the control is not directed only on the data, but they make sure they are aware of any security risks and potential breaches. In order to make sure that no one else has access to the data, one thing 
they can do is to make sure they have all the items in the contract that will list out all the relevant controls on the data accessibilities and the legal issues regarding any breach of security or privacy.

One ultimate data control strategy adopted by some companies in face of the perceived risks associated with privacy is to make sure that the confidential data does not flow out of their companies' wall. Some companies would choose to have their secondary and auxiliary systems which contain very little confidential data on the cloud, less central to the business process, however requiring more flexibility and mobility to be served by the cloud. Meanwhile they keep their core ERP system and financial systems in house. However, sometimes the difference lies in what data is being considered as the most critical and confidential; for example, attitudes towards payroll system can varied. While being financially confidential for some companies, others may regard it as less competitive advantage related and thus less important.

The impacts of the cloud on data strategy are summarized in Table 4.

\begin{tabular}{|l|l|}
\hline Traditional Data Strategy & Cloud Based Data Strategy \\
\hline Data on the ground, stored in data center & Requiring incremental data migration \\
\hline $\begin{array}{l}\text { Traditional data control for in-house data } \\
\text { center }\end{array}$ & $\begin{array}{l}\text { New data control strategy: service } \\
\text { transparency, vendor monitoring, separate } \\
\text { data control strategy }\end{array}$ \\
\hline
\end{tabular}

Table 4: Cloud's Impact on Data strategy

\section{Impact on IT/Business Alignment}

Increasing IT-to-Business Value Speed and Agility: One major benefit of cloud is:

"It enables us to deploy applications in days rather than weeks, with less people involved, at a lower cost, and with better performance."

The cloud improves IT's time-to-benefit by reducing both the time and up-front expenditure for new technology and service adoption, thus making sure that companies can move faster to leverage IT to meet their emerging business needs.

"Although calculating the business return is difficult any time, but now we see benefits coming from the speed, and also less efforts".

Thus cloud computing empowers businesses to increase their competitive advantage by enabling enterprise IT to dynamically respond to changing business needs.

More Attention and Budget to Innovation: To be free from the technical details really helps organizations to focus on their core business and delivering value to their customers. Meanwhile, from the IT investment perspective, the cloud enables organizations to invest more wisely. IT has been the cost center for years, and the traditional IT model requires a significant amount of fixed cost in the annual budget. The actual budget available for funding new IT business initiatives that 
lead to cost reduction, revenue increase and innovation is quite restricted. By deploying a payper use mode, the fixed cost has turned into an operational cost which is more easily scaled up and down based on real business need. In most of the companies, the budget saved from reduced fixed cost can be invested in technologies that are more value generative.

Table 5 summarizes the cloud's impact on IT/Business Alignment:

\begin{tabular}{|l|l|}
\hline Traditional IT/Business Alignment Mode & $\begin{array}{l}\text { Cloud enabled IT/business Alignment } \\
\text { Mode }\end{array}$ \\
\hline $\begin{array}{l}\text { Relative slower project deployment, higher } \\
\text { up-frontal expenditure }\end{array}$ & $\begin{array}{l}\text { Faster implementation, faster IT time to } \\
\text { benefit }\end{array}$ \\
\hline $\begin{array}{l}\text { Large portion of fixed cost, restricted budget } \\
\text { available for innovation }\end{array}$ & $\begin{array}{l}\text { More concentration on core business, } \\
\text { more budget for innovative technology } \\
\text { adoption which will generate more } \\
\text { business value and competitive advantage }\end{array}$ \\
\hline
\end{tabular}

Table 5: Cloud's Impact on IT/business Alignment

\section{THE CLOUD IMPACT MODEL}

Based on the analysis of the above cases, we propose a model to illustrate the impacts of cloud computing on organizational IT strategy in terms of four of its subcomponents: IT architecture, IT management, Data strategy and IT/Business Alignment. Figure 2 provides a graphic depiction of the model for a quick summary. The various components of the model were described above and require no further elaboration. In our opinion, the model is parsimonious and represents the most important elements of the cloud's impact on the organizational IT strategy.

Organizations may find the impact model useful in evaluating their own IT strategy in the adoption of cloud services. We do not expect that each organization will develop the same strategy but each component of the strategy deserves careful attention by senior managers. Various options were discussed for each sub-component and may be selected based on a contingency analysis. Researchers will find the impact model a good starting point to fill in the details as well as develop measures for the various constructs. 


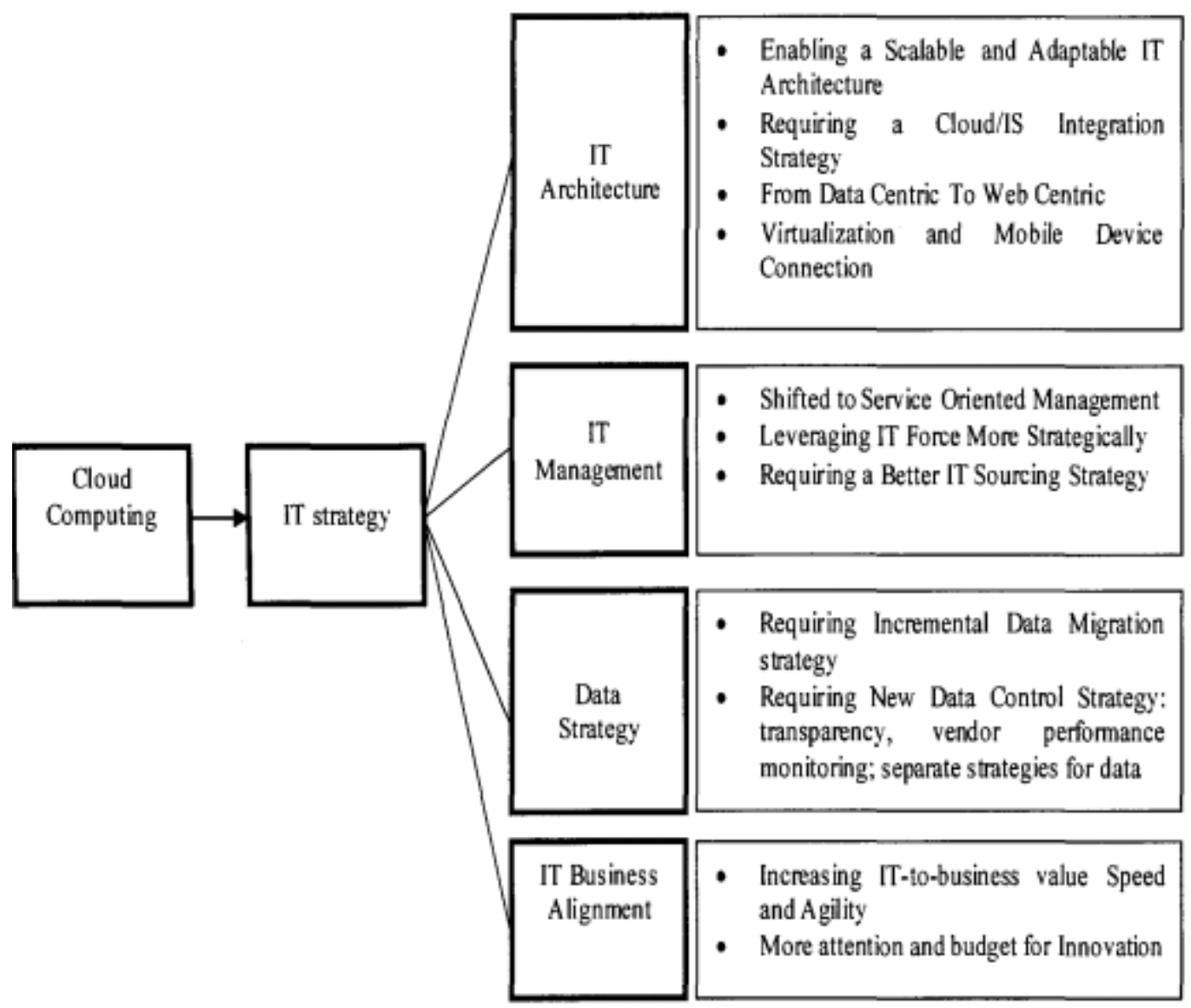

Figure 2: A Model of the Cloud's Impact on Organizational IT strategy

\section{CONTRIBUTIONS AND LIMITATIONS}

One of the major contributions of the study is the premise itself, i.e., the assertion that cloud computing has and should have an impact on the organization's overall IT strategy. Cloud computing is right now a relative new technology for organizations to adopt. However, its strategic importance lies in the fact that it can have a profound impact on the overall IT strategy in order for it to deliver value to the organization. And as the penetration of cloud is ongoing and this trend is likely to only accelerate, the understanding of this impact holds huge practical implications for both current and new adopters. We have identified several impact areas and companies may use them as a benchmark in their own investigations.

Although exploratory, our study appears to be among the first to examine the impacts of cloud computing on IT strategy. As cloud computing is here to stay and grow rapidly, we believe it is a fertile ground for research. The base impact model we provide should serve as an excellent framework to base future explorations on.

One of the limitations of this study is that the impact model is generated from a limited set of data comprised of four cases. Of course, it will be subject to further verification by positivist type research, perhaps a survey based study with a much larger set of companies for increased 
generalization. Also, we exercised no control over the size, type, and industry of the selected companies leading to overall findings which may not be applicable in all cases. Future studies examining the difference between different type and size of companies from various industries may generate more interesting findings. Lastly, we do not examine the types of cloud service adopted by companies; the cloud referred to in this study can either be public or private, delivered as a service, platform or infrastructure. Those differences can have different influences on the organization's experience with the cloud, something that would be of interest to future researchers.

\section{CONCLUSION}

Our study has suggested that the cloud's impact on an organization's IT strategy is significant and multifold. In terms of IT architecture, the cloud has increased the flexibility and scalability by enabling fast implementation and lowering the threshold; it demands a carefully planned strategy to integrate cloud based services with the existing IT infrastructure; the traditional data centric IT has turned into web connectivity centric; virtualization and increasingly connected mobile devices provide immense possibilities for transformation to a modem IT environment. From the IT management perspective, the cloud has resulted in a shift to a service oriented management perspective; it has changed the way organizations use IT power in a more effective and strategic manner; it requires a IT sourcing strategy emphasizing vendor assessment and relationship management. It also has great impact on organization's data strategy requiring a well-planned data migration, demand for service transparency, continuous security check and a separate data control strategy. Lastly, from the IT/business alignment perspective, the cloud has positioned IT in a better place to support business by achieving a new level of IT and business agility and by enabling an increasing focus on the core business.

The impacts of cloud computing are enormous throughout entire organizations. We are in the early stages of this phenomenon and might have just seen the tip of the proverbial iceberg. It is imperative for organizations to carefully plan for this technology and implement it carefully as part of its overall IT strategy. In this light, out study provides important guidelines to organizations so that they will be able to embrace the changes more strategically and better position themselves to reap the benefits while meeting the challenges.

\section{REFERENCES}

1. Ahuja, S.P., \& Rolli, A.C. (2011). Survey of the state-of-the-art of cloud computing. International Journal of Cloud Applications and Computing, 1(4), 36.

2. Armbrust, M., Fox, A, Griffith, R., Joseph, A D., Katz, R., Konwinski, A \& Stoica, I. (2010) A View of Cloud Computing. Communications of the ACM, 53, 4, 50-58.

3. Avanade (2009). 2009 Global Survey of Cloud Computing. Retrieved from http://www.avanade.com/Documents/Research\%20and\%20Insights/fy1Ocloudcomputingexecuti vesummaryfina1314006.pdf 
4. Baets, W. (1992). Aligning information systems with business strategy. The Journal of Strategic Information Systems, 1(4), 205-213.

5. Buyya, R., Yeo, C. S., Venugopal, S., Broberg, J. and Brandic, I. (2009) Cloud Computing And Emerging IT Platforms: Vision, Hype, And Reality For Delivering Computing as The 5th Utility. Future Generation computer systems, 25, 6, 599-616.

6. Catteddu, D. (2010). Cloud Computing: benefits, risks and recommendations for information security, Springer Berlin Heidelberg, 17-17.

7. Chen, D. Q., Mocker, M., Preston, D. S. and Teubner, A (2010). Information systems strategy: reconceptualization, measurement, and implications. MIS quarterly, 34, 2, 233- 259.

8. Cuenca, L., Ortiz, A, \& Boza, A (2011). Architecting Business and IS/IT Strategic Alignment for Extended Enterprises. Studies in informatics and control, 20(1), 8.

9. Gens, F. (2009) "New IDC IT Cloud Services Survey: Top Benefits and Challenges", IDC exchange, Retrieved November 30, 2012 from http://blogs.idc.com/ie/?p=730

10. Glaser, B. G., and Strauss, A L. (1967). The Discovery of Grounded Theory: Strategies for Qualitative Research. London: Wiedenfeld and Nicholson.

11. Glaser, J. P.(2006). Information technology strategy: three misconceptions. Journal of Healthcare Information Management, 20, 4, 69.

12. Gottschalk, P. (1999). Strategic information systems planning: the IT strategy implementation matrix. European Journal of Information Systems, 8(2), 107-118.

13. Gustas, R. and Gustiene, P. (2004) Towards the Enterprise Engineering Approach for Information System Modeling across Organizational and Technical Boundaries, Enterprise Information Systems V; Kluwer, Netherlands, 204-215.

14. Henderson, J. C. and Venkatraman, N. (1993) Strategic Alignment: Leveraging Information Technology for Transforming Organizations, IBM Systems Journal, 32, 1,4- 16.

15. Hyek, P. (2011) Cloud computing issues and impacts, Ernest \&Young, report 2011, Global Technology Industry Discussion Series, retrieved from http://www.ey.com

16. Iyer, B., and Henderson, J. C. (2010). Preparing for the future: understanding the seven capabilities of cloud computing. MIS Quarterly Executive, 9(2),117-131.

17. Jensen, M., Schwenk, J., Gruschka, N. and Iacono, L. L. (2009). On technical security issues in cloud computing. In Cloud Computing, 2009. CLOUD'09. IEEE International Conference, 109-116. 
18. Joint, A, Baker, E., \& Eccles, E. (2009). Hey, you, get off of that cloud? Computer Law \& Security Review, 25, 3, 270-274.

19. Khajeh-Hosseini, A, Greenwood, D. and Sommerville, I. (2010). Cloud migration: A case study of migrating an enterprise it system to I-aas. In Cloud Computing (CLOUD), 2010 IEEE 3rd International Conference, 450-457

20. King, W. R. (1978). Strategic planning for management information systems.MIS quarterly, 27-37.

21. Luftman, 1. N., Lewis, P. R., \& Oldach, S. H. (1993). Transforming the enterprise: The alignment of business and information technology strategies. IBM Systems Journal, 32, 1, 198221.

2. Lundell, B., McKnight, 1. and Gahm, J. (2011) Cloud Computing Adoption Trends: SoftwareAnd Infrastructure-As-A-Service Usage among Enterprise and Midmarket Organizations, Retrieved from http://www.esg-global.com/default/assetslFile/ESGResearch-Report-CloudTrends-Abstract-May-11.pdf

23. Mack, R. and Frey, N. (2002) Six Building Blocks for Creating Real IT Strategies. Strategic Analysis Report, R-17-3607, Gartner Research. Retrieved from http://www.wx1359.com/tui/ITM501/modules/ module4/71983Gartner\%20IT\%20Strategy\%20Bluiding\%20Blocks.pdf

24. Magoulas, T. and K. Pessi (1998). Strategisk IT-management. Institutionen for informatik, Handelshogskolan vid Goteborgs universitet. Goteborg, Giiteborgs universitet: 458.

25. Marston, S., Li, Z., Bandyopadhyay, S., Zhang, J. and Ghalsasi, A (2011) Cloud computingThe business perspective. Decision Support Systems, 51,1,176-189.

26. Mell, P., and Grance, T. (2009). The NIST Definition of Cloud Computing. Retrieved from http://www.nist.gov/itllcloud/upload/cloud-def-v15.pdf

27. Misra, SC and Mondal, A (2011). Identification of a Company's Suitability for the Adoption of Cloud Computing and Modeling Its Corresponding Return on Investment. Mathematical and Computer Modeling, 53(3-4), 504-521

28. Motahari-Nezhad, H. R., Stephenson, B. and Singhal, S. (2009). Outsourcing business to cloud computing services: Opportunities and challenges. IEEE Internet Computing, Palo Alto, 10 .

29. Ross, 1. W., \& Westerman, G. (2004). Preparing for utility computing: The role of IT architecture and relationship management. IBM systemsjournal, 43(1), 5-19.

30. Strauss, A, and Corbin, 1. (1994). Grounded theory methodology. Handbook of qualitative research, 273-285. 
31. Ward, B. T., and Sipior, J. C. (2010). The Internet jurisdiction risk of cloud computing. Information Systems Management, 27(4), 334-339.

32. Yanosky, R. (2008). From users to choosers: The cloud and the changing shape of enterprise authority. The tower and the cloud, 126. 